\title{
LA-UR $=96-3531$
}

Title:

COORDINATED GROUND-BASED AND GEOSYNCHRONOUS SATELLITE-BASED MEASUREMENTS OF AURORAL PULSATIONS

$$
\text { CONF- } 9609292--1
$$

Author(s):

Submitted to:

David M. Suszcynsky

Joseph E. Borovsky

Michelle F. Thomsen

David J. McComas

Richard D. Belian

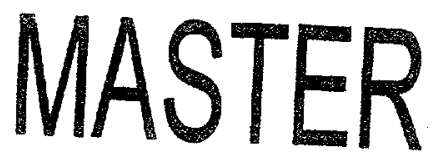

SPIE Proceedings on the 23rd European Conference on

Optical Methods in the Atmosphere

September 2-6, 1996

Kiev, Ukraine

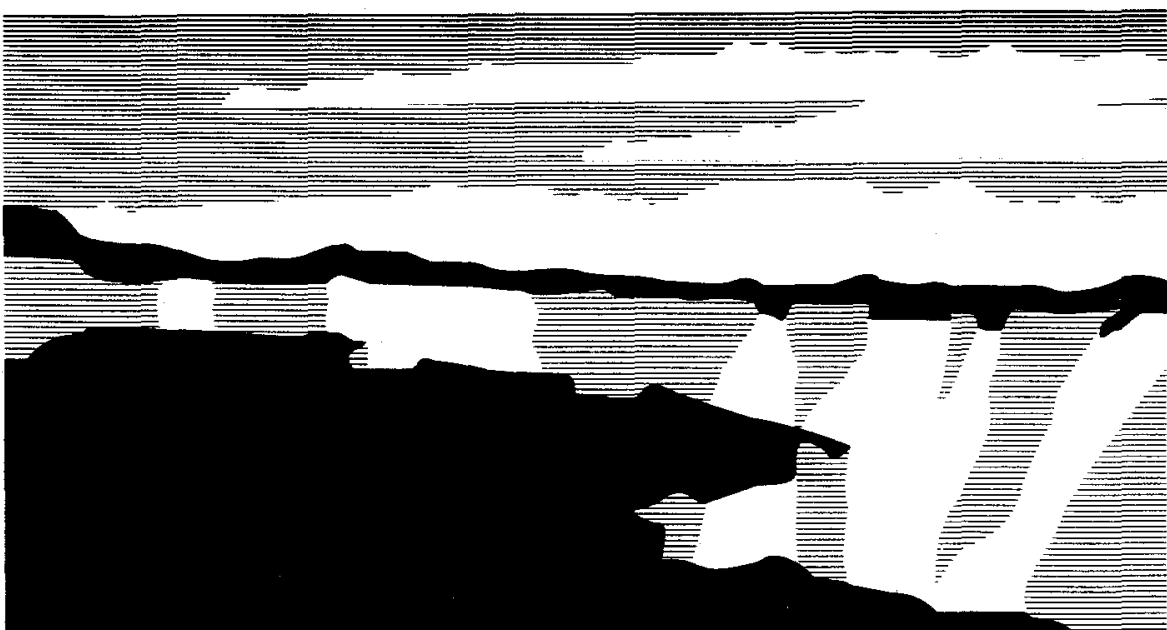

NATIONAL LABORATORY

Los Alamos National Laboratory, an affirmative action/equal opportunity employer, is operated by the University of California for the U.S. Department of Energy under contract $W-7405-E N G-36$. By acceptance of this articie, the publisher recognizes that the U.S. Government retains a nonexclusive, royalty-free license to publish or reproduce the published form of this contribution, or to allow others to do so, for U.S. Government purposes. The Los Alamos National Laboratory requests that the publisher identify this article as work performed under the auspices of the U.S. Department of Energy. 


\section{DISCLAIMER}

This report was prepared as an account of work sponsored by an agency of the United States Government. Neither the United States Government nor any agency thereof, nor any of their employees, makes any warranty, express or implied, or assumes any legal liability or responsibility for the accuracy, completeness, or usefulness of any information, apparatus, product, or process disclosed, or represents that its use would not infringe privately owned rights. Reference herein to any specific commercial product, process, or service by trade name, trademark, manufacturer, or otherwise does not necessarily constitute or imply its endorsement, recommendation, or favoring by the United States Government or any agency thereof. The views and opinions of authors expressed herein do not necessarily state or reflect those of the United States Government or any agency thereof. 


\section{DISCLAIMER}

Portions of this document may be illegible in electronic image products. Images are produced from the best available original document. 
Coordinated ground-based and geosynchronous satellite-based measurements of auroral pulsations

David M. Suszcynsky, Joseph E. Borovsky, Michelle F. Thomsen, David J. McComas, Richard D. Belian

\author{
Los Alamos National Laboratory \\ Space \& Atmospheric Sciences Group \\ Los Alamos, NM 87545
}

\begin{abstract}
We describe a technique that uses a ground-based all-sky video camera and geosynchronous satellite-based plasma and energetic particle detectors to study ionosphere-magnetosphere coupling as it relates to the aurora. The video camera system was deployed in Eagle, Alaska for a seven month period at the foot of the magnetic field line that threads geosynchronous satellite 1989-046. Since 1989-046 corotates with the earth, its footprint remains nearly fixed in the vicinity of Eagle, allowing for routine continuous monitoring of an auroral field line at its intersections with the ground and with geosynchronous orbit. As an example of the utility of this technique, we present coordinated ground-based and satellitebased observations during periods of auroral pulsations and compare this data to the predictions of both the relaxation oscillator theory and flow cyclotron maser theory for the generation of pulsating aurorae. The observed plasma and energetic particle characteristics at geosynchronous orbit during pulsating aurorae displays are found to be in agreement with the predictions of both theories lending further support that a cyclotron resonance mechanism is responsible for auroral pulsations.
\end{abstract}

Keywords: aurora, pulsating aurora, geosynchronous orbit, all-sky camera, ionosphere, magnetosphere

\title{
II. INTRODUCTION
}

The auroral ionosphere and its corresponding magnetospheric domains have been intensively studied by both ground-based and in-situ-based instrumentation for over 30 years. Despite the vast amount of knowledge that has been gained from these studies, the basic mechanisms that govern the generation of most auroral forms (in particular, discrete auroral arcs and auroral pulsations) have yet to be conclusively identified. Much of the difficulty in identifying these mechanisms relates to the fact that the generation regions and particle acceleration regions for a specific auroral form are usually far removed from, and in radically different plasma environments than, the region where precipitating auroral particles manifest themselves as visible auroral activity. This system complexity effectively precludes the possibility of using single-point measurements for the positive identification of auroral generator mechanisms.

Over the years, there have been numerous attempts to make magnetically conjugate multi-point, multi-phenomenology observations of auroral activity in order to identify and study auroral generator mechanisms. The most promising studies have involved ground-based auroral imagery stationed at locations magnetically conjugate to satellite-based plasma, particle, and magnetic/electric field instrumentation ${ }^{1-7}$. However, the results of most of these studies have been limited by brief or marginally conjugate satellite/ground station alignments and/or short-term ground campaigns. In this paper, we describe our efforts to field and operate a system that provides continuous, long-term monitoring of auroral activity at a ground station that is magnetically connected to a geosynchronous satellite. Our intent is to collect long-timescale data sets that can be used to address, both on a per case and statistical basis, the mapping of magnetospheric domains into their auroral counterparts and the identification of and comparison between existing theories of auroral generator mechanisms. Geosynchronous orbit is optimal for this type of study for two reasons: (1) since a geosynchronous satellite corotates with the earth, its magnetic footprint on the earth remains fixed, allowing for a continuous long-term monitoring of a magnetic field line with fixed, ground-based equipment, and (2) geosynchronous orbit samples several key regions of the magnetosphere that are believed to be source regions for various auroral forms: the ion and electron plasma sheets, the trough, and the plasmasphere.

This paper is organized as follows. After the introduction, section II describes the observation technique and instrumentation that was used for data collection. A data example that illustrates the usefulness and effectiveness of the approach is described in sections III and IV. Section III presents some preliminary results of ground and satellite-based observations of pulsating aurorae and section IV discusses these results and compares them to the predictions of two leading theories on the generation of pulsating aurora. 


\section{EXPERIMENTAL TECHNIQUE AND INSTRUMENTATION}

The experimental setup consisted of a ground-based all-sky video camera that was fielded in Eagle, Alaska at the foot of the magnetic field line that threads geosynchronous satellite 1989-046. The video camera system consisted of an intensified $\mathrm{CCD}$ with an unfiltered f1.6 telecentric lens. The camera automatically began recordings in VHS format whenever the sun was below $-13^{\circ}$ elevation and the moon was below the horizon. Since 1989-046 corotates with the earth, its footpoint remains fixed in the vicinity of Eagle, allowing for routine continuous monitoring of an auroral field line by the video camera. The satellite carried two instruments, the Magnetospheric Plasma Analyzer (MPA) ${ }^{8}$ and the Synchronous Orbit Particle Analyzer (SOPA) ${ }^{9}$. MPA is an electrostatic analyzer that is sensitive to electrons in the $30 \mathrm{eV}$ to $40 \mathrm{keV}$ energy range and ions in the $1 \mathrm{eV}$ to $40 \mathrm{keV}$ energy range. The spin axis points towards the earth with six individual detectors sampling the polar angle range of $+1-66^{\circ}$ about the spacecraft spin equator. Thus, the instrument can sample field-aligned $\left(0^{\circ}\right.$ and $180^{\circ}$ ) particles and also particles eastward $\left(90^{\circ}\right)$ and westward $\left(90^{\circ}\right)$ along the satellite orbit. The spacecraft spins once every 10 seconds and collects a full distribution function every 86 seconds. The SOPA instrument consists of three solid state detectors looking at $30^{\circ}, 60^{\circ}$, and $90^{\circ}$ from the earth-pointing spin-axis. It has a sampling period of $320 / 640$ milliseconds and is sensitive to electrons in the $50 \mathrm{keV}$ to greater than $1.5 \mathrm{MeV}$ energy range, protons in the $50 \mathrm{keV}$ to 50 Mev energy range, and other ions in the $1 \sim 20 \mathrm{MeV}$ energy range, the exact range depending on ion mass. The simultaneous operation of both the MPA and SOPA instruments provided a comprehensive survey of the geosynchronous particles (energies, densities, fluxes and temperatures) that interact with the geosynchronous environment to produce visible auroral manifestations in the ionosphere.

The campaign described in this paper ran from October 1, 1994 to mid-April, 1995. During this time period, there were over 70 days in which simultaneous camera and satellite observations of auroral activity were collected.

\section{RESULTS OF PULSATING AURORA STUDY}

As a first step in the analysis of the data set and as a means of demonstrating the overall utility of this technique, we have completed a preliminary survey of the characteristics of the geosynchronous environment during auroral pulsation periods. Auroral pulsations generally occur in the post-midnight sky during the recovery phase of a substorm and are observed as intensity fluctuations of randomly located, irregularly shaped, patches or arc segments, each form having a pulsation frequency on the order of $0.1-3 \mathrm{~Hz}$. Adjacent pulsating forms typically pulsate out of phase, have dimensions on the order of $10-200 \mathrm{~km}$, and reside at pre-dominantly e-region and lower f-region altitudes. The generation mechanism for pulsating aurora has yet to be sufficiently described but is believed to operate at geosynchronous orbit and to rely on a periodic waveparticle resonance that scatters electrons into the loss cone. Reviews of auroral pulsation phenomenology and theory can be found, for example, in papers by Johnstone ${ }^{10}$, Roryvik and Davis ${ }^{11}$, Davidson ${ }^{12}$ and Nemzek et al. ${ }^{7}$.

Pulsating aurorae were chosen for the first phase of this study since they typically occur when the magnetosphere is in a relatively unstretched condition (recovery phase). This condition generally results in a more accurate mapping of the magnetic footprint of the satellite to the ground. Figure 1 illustrates the magnetic field line mapping of the 1989-046 footpoint during quiet $(\mathrm{Kp}=0)$ and moderately active $(\mathrm{Kp}=4)$ periods using the Tsyganenko ${ }^{13} 1987$ magnetic field line mapping model. The approximate field-of-view of the all-sky camera is indicated by the circle. As can be seen, the footprint mapping is more localized during quieter time periods. In addition, for a large range of magnetic conditions, the footpoint always remains well within the field-of-view of the camera. Since each of the pulsating aurora cases that were studied for this paper appeared across the entire field-of-view of the camera, we are fairly confident that for each case studied, the satellite sampled the geosynchronous environment that was magnetically connected to and responsible for the auroral pulsations as seen by the all-sky camera.

For this study, 17 pulsating aurora cases were analyzed. Each case produced moderately strong pulsations that covered the majority of the all-sky camera field-of-view. Figure 2 shows a typical characterization of the pulsations using both the ground-based and satellite-based data sets for the night of November 1, 1994. The bottom panel indicates the type of auroral activity as seen by the all-sky camera $(\mathrm{NA}=$ no activity, $\mathrm{QA}=$ quiet arcs, $\mathrm{AA}=$ active arcs, $\mathrm{B}=$ auroral breakup, $\mathrm{PA}=$-puisating aurora). The second and third panels show the MPA electron energy spectrogram (color proportional to energy flux) and look azimuth plot (color proportional to number flux) for the same time interval. The fourth panel shows the SOPA electron flux as measured by the $50 \mathrm{keV}-75 \mathrm{keV}$ energy channel, and the fifth panel plots the MPA parameter "theta" Theta is the 
angle between the geomagnetic equator and the local magnetic field vector. It is inferred by noting symmetries in the MPA particle distribution functions and is used here as a measure of how stretched the magnetosphere is. A theta equal to $90^{\circ}$ implies a nearly unstretched (i.e. dipolar) magnetospheric configuration.

In figure 2, the all-sky camera is turned on at about 0615 UT at which time there is no observed auroral activity. The electron energy spectrogram at this time indicates that the satellite is the plasmasphere/trough region (low flux, low energy electrons). At about 0700 UT, quiet and active arcs begin to appear in the vicinity of the footpoint, in association with the entry of the satellite into the electron plasma sheet (electron energies increasing to 1-10 keV levels). As can be seen in the theta plot, the arrival of the plasma sheet at the satellite corresponds in time to the maximum stretch of the magnetosphere. In other words, the appearance of the plasma sheet in the satellite data is more likely due to the motion of the plasma sheet past the satellite rather than a satellite excursion into the plasma sheet. This suspicion is born out by the events immediately proceeding the appearance of the plasma sheet. At about $0810 \mathrm{UT}$, a moderately strong injection of energetic electrons is observed by SOPA indicating a substorm onset. This event coincided in time with an isotropic increase in MPA electron flux and with the occurrence of an auroral breakup as seen from the ground. Theta immediately drops in value at this time as the magnetotail snaps back to a dipolar configuration. The recovery phase of the substorm begins at the peak of the electron injection and is characterized in the MPA data by an anisotropization of the $8-40 \mathrm{keV}$ electrons (pancake distribution, $90^{\circ}$ and $180^{\circ}$ ) and in the all-sky data by the appearance of strong, widespread, pulsations. The above-mentioned anisotropization is better observed in the recovery phase of the second substorm cycle (injection peak at 1120 UT). At this point the pancake distribution is established again after the isotropy produced by the injection, and then persists well into the morning hours interrupted only once at about 1210 UT when yet a third substorm/injection occurs. This third cycle was particularly interesting in that the pulsations from the recovery phase of the 1120 UT injection were "re-energized" in both brightness and frequency, just prior to, and during the growth phase of the 1210UT substorm. This effect was observed on several occasions in the 17 cases studied.

\section{DISCUSSION OF RESULTS}

Based on the representative results of figure 2, we can make the following statements concerning the characterization of geosynchronous orbit during auroral pulsation activity. Pulsations (1) are observed as a recovery phase phenomena, commencing within a few minutes of the $50 \mathrm{keV}-75 \mathrm{keV}$ injection electron flux maximum, (2) are often "re-energized" during the growth and expansion phase of subsequent substorm cycles, (3) only occur for energetic particle fluxes between 6 $\times 10^{6} \mathrm{~cm}^{-2} \mathrm{~s}^{-1} \mathrm{sr}^{-1}$ to $6 \times 10^{7} \mathrm{~cm}^{-2} \mathrm{~s}^{-1} \mathrm{sr}^{-1}$, i.e. between the weak and strong diffusion limits ${ }^{14,15}$, and (4) only occur during strong electron pitch-angle anisotropies (pancake distribution) in the $1 \mathrm{keV}$ to $40 \mathrm{keV}$ energy range. Of these observations, (1) has been a well-known fact since the first discovery of injection events[ref], (2) and (3) have been occasionally observed or reported $^{7,15}$ and are significant enough to warrant further study, and (4) represents a unique experimental confirmation of the electron pitch-angle distribution predicted by most pulsation theories. Additionally, the results (1), (2), and (3) are in agreement with the results of Nemzek et al. ${ }^{7}$ despite the fact that the Nemzek et al. ${ }^{7}$ footpoint was low on the horizon, making one-to-one comparisons between auroral activity and orbital data difficult.

The above results can be compared to two of the leading theories on auroral pulsation generation, the relaxation oscillator theory ${ }^{12,16}$ and the flow cyclotron maser theory ${ }^{17,18}$. In the relaxation oscillator theory, a pitch-angle anisotropy near the geomagnetic equator favors the growth of an instability that produces VLF whistler-mode waves. These waves, in turn, undergo cyclotron resonance with counterstreaming electrons, resulting in a scattering of the electrons into a loss cone. Consequently, this filling of the loss cone reduces the growth of the waves. Once the electrons precipitate into the ionosphere, the anisotropy is reestablished and the process repeats itself resulting in a periodic precipitation of electrons. The flow cyclotron maser model is similar to the relaxation oscillator model in that it invokes the cyclotron resonance mechanism. However, it also provides a theoretical basis for the entry of fresh injection electrons into the pulsation flux tube. The strength of the resonance that leads to the precipitation of these electrons is controlled by the cold plasma density within the flux tube. This cold plasma density must be on the order of $1 \mathrm{~cm}^{-3}$ for the mechanism to operate.

Our results validate several aspects of the above-mentioned theories. The pitch-angle distribution plot in figure 2 , as was the case in the other 16 examples studied, shows a dominant anisotropy in pitch-angle during pulsation events. Although MPA does not have the time or spatial resolution to discern the emptying and refilling of the loss cone, the confirmation that this general anisotropy is necessary for the occurrence of pulsations, lends further support to the idea of a generation process 
dependent upon pitch-angle diffusion into the loss cone. The pulsations were also found to occur only when the energetic electron flux was within the $6 \times 10^{6} \mathrm{~cm}^{-2} \mathrm{~s}^{-1} \mathrm{sr}^{-1}$ to $6 \times 10^{7} \mathrm{~cm}^{-2} \mathrm{~s}^{-1} \mathrm{sr}^{-1}$ range. This is in agreement with the requirement from the relaxation oscillator theory that the flux be less than the strong diffusion limit $\left(\sim 5 \times 10^{7} \mathrm{~cm}^{-2} \mathrm{~s}^{-1} \mathrm{sr}^{-1}\right)$ and with the flow cyclotron maser requirement that the energetic electron density be greater than 10-3 times the cold plasma density. Additionally, the cold plasma density has been inferred by assuming charge neutrality and measuring the cold ion density. This is within the range required by theory. Finally, the observation that pulsation intensities are enhanced during the growth and expansion phase of subsequent substorms is a strong indication that the lowest energy energetic electrons that are injected into geosynchronous orbit are the same electrons that precipitate to the ground during pulsation events. The fact that pre-existing patches of pulsations are reenergized during subsequent substorms indicates that the conditions that determine patch location are independent of the existence of energetic electrons (i.e. supports the enhanced density flux tube picture).

In summary, the data presented above gives further insight into the plasma and energetic particle conditions that exist at geosynchronous orbit during auroral pulsation activity. The observed conditions are found to be in generally agreement with those predicted by both the relaxation oscillator theory ${ }^{12,16}$ and the flow cyclotron maser theory ${ }^{17.18}$ for auroral pulsation generation. Future work with this data set will include a quantification of anisotropy levels as a function of particle energy and pulsation intensity as a means of further testing of observations to theory.

\section{ACKNOWLEDGEMENTS}

The authors wish to thank Hal DeHaven, Bob Nemzek, Geoff Reeves, Elizabeth Brunn and Steve Schum, at Los Alamos National Laboratory for valuable discussions, and for their data archival and analysis efforts. The video camera system was fielded and operated by Tom Hallinan of the Geophysical Institute, University of Alaska. This work was sponsored by the United States Department of Energy and by NASA grant W- 18955.

\section{REFERENCES}

1. Mende, S. B., R. D. Sharp, and E. G. Shelley, "Coordinated observations of the magnetosphere: the development of a substorm," J. Geophys. Res., 77, 4682-4699, 1972.

2. Akasofu, S.-I., S. DeForest, and C. McIlwain, Planet. Space Sci., 22, 25, 1974.

3. Mende, S. B., and E. G. Shelley, "Coordinated ATS-5 electron flux and simultaneous auroral observations," J. Geophys. Res., 81, 97-110, 1976.

4. H. Eather, S. B. Mende, and R. J. R. Judge, "Plasma injection at synchronous orbit and spatial and temporal auroral morphology," J. Geophys. Res., 81, 2805-2824, 1976.

5. Meng, C.-I., B. Mauk, C. E. McIlwain, "Electron precipitation of evening diffuse aurora and its conjugate electron fluxes near the magnetospheric equator," J. Geophys. Res., 84, 2545-2558, 1979.

6. Shepherd, G. G., et al., "Plasma and field signatures of poleward propagating auroral precipitation observed at the foot of the geos 2 field line," J. Geophys. Res., 85, 4587-4601, 1980.

7. R. J. Nemzek, R. Nakamura, D. N. Baker, R. D. Belian, D. J. McComas, M.F. Thomsen, and T. Yamamoto, "The relationship between pulsating auroras observed from the ground and energetic electrons and plasma density measured at geosynchronous orbit," J. Geophys. Res., 100, 23935-23944, 1995.

8. McComas, D. J., S. J. Bame, B. L. Barraclough, J. R. Donart, R. C. Elphic, J. T. Gosling, M. B. Moldwin, K. R. Moore, and M. F. Thomsen, "Magnetospheric plasma analyzer: initial three-spacecraft observations from geosynchronous orbit,"J. Geophys. Res., 98, 13453-13465, 1993.

9. Belian, R. D., G. R. Gisler, T. Cayton, and R. Christiansen, "High-Z energetic particles at geosynchronous orbit during the great solar proton event series of october, 1989," J. Geophys. Res., 97, 16897-16906, 1992.

10. A. D. Johnstone, "The mechanism of pulsating aurora," Annales Geophys., 1, 397-419, 1983.

11. Royrvik, O., and T. N. Davis, "Pulsating aurora: local and global morphology," J. Geophys. Res., 82, 4720-4740, 1977.

12. Davidson, G. T., "Pitch-angle diffusion and the origin of temporal and spatial structures in morningside aurorae," Space Sci. Rev., 53, 45-82, 1990.

13. Tsyganenko,

14. Kennel, C. F., and H. E. Petschek, "Limit on stably trapped particle fluxes," J. Geophys. Res., 71, 1-28, 1966.

15. Baker, D. N., P. Stauning, E. W. Hones, P. R. Higbie, and R. D. Belian, "Strong electron pitch angle diffusion 

.+1

Figure 1. Map showing the location of the all-sky camera site in Eagle, Alaska, a circle representing the approximate fieldof-view of the camera, and the Tsyganenko ' 87 magnetic field-line mappings of the footpoint of satellite 1989-046 for quiet $\left(\mathrm{K}_{\mathrm{p}}=0\right)$ and active $\left(\mathrm{K}_{\mathrm{p}}=4\right)$ magnetic conditions.

Figure 2. Ground and satellite data summaries as a function of time for the pulsating aurorae events of November 1, 1994. See text for description. 